\title{
Environment-health link in a context of urban agricultures: studies of oral exposure to pollutants in order promote the human health
}

\author{
Camille Dumat $^{1,2,3} \cdot$ Aurélie Pelfrêne $^{4} \cdot$ Muhammad Shahid $^{5}$
}

Received: 6 February 2019 / Accepted: 15 February 2019 / Published online: 20 May 2019

๑) Springer-Verlag GmbH Germany, part of Springer Nature 2019

This ESPR special issue includes a selection of papers presented at the international congress "Sustainable Urban Agriculture: Vector for the Ecological Transition" (UA\&ET), which is focused in a special session on the link between environment and human health, and which was held on June 2017 in Toulouse, France.

According to the Food and Agriculture Organization (FAO), $60 \%$ of humanity lives actually in urban areas and forecasts for 2050 are $80 \%$ (with +3 billion people on earth). The anticipated increase in the world's population and rapid, unchecked and unplanned urbanization will exert tremendous pressure on food demand and quality. The development of urban agriculture (UA) is one of the keys to food survival of humanity. Many UA projects are therefore developing in the world: various urban farms (different sizes, organization, technologies...), aquaponics productions, collective gardens possibly rooftop, fruit trees in collective housing, etc. Multidisciplinary innovations optimize the efficiency of urban metabolism, promote sustainable food in connection with the circular economy, the quality of food production and ecosystems and participate in the well-being (social, health for all, edible landscapes, etc.).

Actually, pollutions are often observed in urban areas: near roads, agricultural, and industrial activities that took place over the centuries. Many chemicals can circulate or

\section{Responsible editor: Philippe Garrigues}

Aurélie Pelfrêne

aurelie.pelfrene@yncrea.fr

1 CERTOP UMR 5044 CNRS - Jean Jaurès - Maison de la Recherche, Université Toulouse, Bat B26, 5 allée Antonio Machado, F-31058 Toulouse cedex 9, France

2 Toulouse INP-ENSAT, Toulouse cedex, France

3 Réseau-Agriville, Castanet-Tolosan, France

4 LGCgE - Yncréa Hauts-de-France, 48 boulevard Vauban, BP41290, 59014 Lille cedex, France

5 Department of Environmental Sciences, COMSATS University Islamabad, Vehari-Campus, Islamabad, Pakistan accumulate in urban soils and cultures. Moreover, because of the complexity of bio-physicochemical mechanisms involved in the transfer of substances in terrestrial ecosystems, scientists can rarely answer the questions about pollution asked by the citizens. This implies the need for environmental-friendly practices and environmentally sustainable approaches regarding UA and the development of citizen sciences. Promoting the development of sustainable techniques to monitor, assess and manage the pollutions and their impacts are therefore major scientific and social challenges to produce healthy food in densely populated urban areas. Operational collaboration between researchers, citizens, and managers is therefore crucial for integrated sustainable solutions regarding the health and environment. Indeed, environmental regulations if it evolves, remains incomplete: for example, there are no French regulatory threshold values for total concentrations of pollutants in soils; in Europe, lead, cadmium, and mercury (EC No 466/2001) are the only regulated metals in marketed foods; or a threshold of $0.1 \%$ (weight) is fixed for the chemical substances analyzed in the commercial articles.

Nowadays, health risk assessment is highly topical, especially in marketable foods produced by UA. Health risk assessment indices trace the possible route and level of exposure to pollutants to avoid health hazards and to make timely decisions/policies/management. Reliable assessment of human health risks from exposure to pollutants in soils depends on their bioavailability and chemical speciation. Because in vivo animal assays to estimate pollutant bioavailability are unethical and costly, in vitro assays have been developed to measure oral bioaccessibility of pollutants and then assess human bioavailability. Information on pollutant human bioaccessibility, in contrast to total contaminant concentrations: (i) offers an effective decision-support tool and an opportunity to better refine contaminant exposure assessments and aid decisionmaking, and (ii) can, therefore, promote a more proportionate and cost-effective assessment of contaminated land.

In that context, the ESPR special issue focused on environment-health for urban agriculture projects examines more particularly, human oral exposure to pollutants 
and the following skills: strategies to reconciling urban production quality and environmental pollutions; how to communicate effectively with different stakeholders on risk management? Assessment and management of nutrients/pollutants flows and levels in the environment and human exposure.

The brief introduction of articles accepted for SI: UA\&ET2017 is given as follows:

In the paper titled "Health risk assessment of drinking arsenic containing groundwater in Hasilpur, Pakistan: Effect of sampling area, depth and source," Tabassum et al. evaluated As contamination and associated health risks in unexplored groundwater of Hasilpur-Pakistan. A total of 61 groundwater samples were collected from different areas (rural and urban), sources, and depths. It was found that $41 \%$ of the water samples contained As $(\geq 5 \mu \mathrm{g} / \mathrm{L})$ and the major contamination was found in urban areas. Furthermore, health risk and cancer risk due to As contamination were also assessed with respect to average daily dose (ADD), hazard quotient (HQ), and carcinogenic risk (CR). The values of HQ and CR of As in Hasilpur were up to 58 and 0.00231 , respectively. The current study proposed the proper monitoring and management of well water in Hasilpur to minimize the As-associated health hazards.

In the paper titled "Heavy metal availability, bioaccessibility, and leachability in contaminated soil: effects of pig manure and earthworms," Li et al. conducted a pot experiment and a leaching experiment to investigate the effects of earthworms and pig manure on $\mathrm{Cd}, \mathrm{Pb}$, and $\mathrm{Zn}$ immobility; in vitro bioaccessibility; and leachability under simulated acid rain. Application of earthworm alone did not contribute to the remediation of heavy metal polluted soils. Considering the effects on heavy metal immobilization and cost, the application of $6 \%$ manure was an alternative approach for treating contaminated soils. These findings provided a valuable information for risk management during immobilization of heavy metals in contaminated soils. In the paper titled "The role of epicuticular waxes on foliar metal transfer and phytotoxicity in edible vegetables: case of Brassica oleracea species exposed to manufactured particles," Dappe et al. investigated the phytotoxicity induced by foliar transfer of atmospheric particles of industrial/urban origin. Besides the location of the metalrich particles $\left(\mathrm{PbSO}_{4}, \mathrm{CuO}\right.$, and $\left.\mathrm{CdO}\right)$ on/in the leaves by microscopic techniques, photosynthetic activity measurements, genotoxicity assessment, and quantification of the gene expression have been studied for several durations of exposure. These findings provided a useful information for risk management from the foliar absorption of metals. In the paper titled "Residues of endosulfan in cotton growing area of Vehari-Pakistan: an assessment of knowledge and awareness of pesticide use and health risks," Ahmad et al. carried out a study based on self-reported information collected from selected farmers to determine their technical knowledge and awareness about pesticide use and associated environmental and health risks. Soil contamination by routinely used persistent organochlorine pesticide was also evaluated. Survey data revealed very low literacy rate (on an average 9th grade education) and technical knowledge (almost missing) of the farmers in Vehari District. The farmers are unable to fully read and understand the instructions about the use of pesticide marked on the containers. They are not fully aware of pesticide persistence and toxicity (73\%), unable to identify cotton pests and diseases $(86 \%)$, and do not know which crop to grow in cotton adjacent fields (100\%). Data also revealed that the farmers $(100 \%)$ do not follow safety measure during pesticide application and are unaware of pesticide toxicity symptoms in human as well as the basic first-aid practices (89\%). Findings are of great use for policymaking in Pakistan to minimize pesticide risks in Pakistan.

In the paper titled "Influence of earthworms bioturbation on metal phytoavailability and human gastric bioaccessibility," Lévêque et al. set up an experiment to examine the mechanisms involved in complex soil-earthwormplant ecosystems using lettuce cultivated in controlled conditions with RHIZOtest ${ }^{\circledR}$ devices. Metal $(\mathrm{Pb}, \mathrm{Cd}, \mathrm{Cu}$, and $\mathrm{Zn}$ ) transfer and bioaccessibility were for the first time compared for urban polluted soil without and with bioturbation and earthworm casts. Results showed that earthworm bioturbation increased the phytoavailability of all the metals. These data are important to promote sustainable agriculture activities in urban areas; actually, databases concerning different experimental conditions are needed to develop decision support tools.

In the paper titled "Vermicompost addition influences symbiotic fungi communities associated with leek cultivated in metal-rich soils," Pierart et al. studied the influence of vermicompost amendments on symbiotic fungal communities associated with Allium porrum L. grown in metal-rich soils (geogenic or anthropogenic contamination). Vermicompost addition led to a dramatic change in the fungal community with a loss of diversity in both cases, which suggests being careful while using composts when growing edibles in contaminated soils.

In the paper titled "Airborne foliar transfer of particular metals in Lactuca sativa L.: Translocation, phytotoxicity and bioaccessibility," Xiong et al. exposed lettuce plants to $\mathrm{PbO}, \mathrm{CuO}$, and $\mathrm{CdO}$ particulate matters by the foliar pathway. Substantial levels of metals were observed in the directly exposed edible leaves and newly formed leaves of lettuce, highlighting both the possible metal transfers throughout the plant and the potential for human exposure after plant ingestion. The study highlights the fate and toxicity of metal-rich particulate matters, especially 
in highly populated urban areas, which are increasingly cultivated to promote local food.

In the paper titled "From environmental data acquisition to assessment of gardeners' exposure: Feedback in an urban context highly contaminated with metals," Pelfrêne et al. presented a feedback on a participatory program initiated in 115 private kitchen gardens located in northern France in order to better assess the local population's exposure to $\mathrm{Cd}$ and $\mathrm{Pb}$ induced by the past activities of a lead smelter. The challenge included contributing to the database of urban garden soils with the collection of a large number of samples: 1525 crops, 708 topsoils, and 52 samples of self-produced compost. This study aimed to raise awareness and generate functional recommendations to reduce human exposure and to provide useful data that could be considered in other environmental contexts. In the paper titled "Foliar uptake of arsenic nanoparticles by spinach: an assessment of physiological and human health risk implications," Shahid et al. evaluated the foliar uptake of arsenic, accumulation of As in different plant organs, its toxicity, and its defensive mechanism in spinach after foliar application of As in the form of nanoparticles. Results indicate that spinach can absorb As via foliar pathways and can translocate it towards root tissues disturbing the plant metabolism. So, air quality needs to be considered and monitored continuously for the human health risk assessment and quality of vegetables cultivated on polluted soils.

Publisher's note Springer Nature remains neutral with regard to jurisdictional claims in published maps and institutional affiliations.

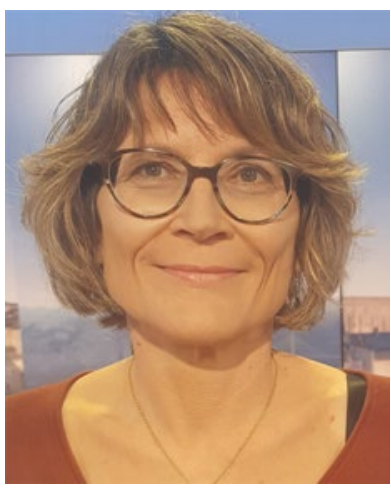

Pr. Camille Dumat is now a researcher at the CERTOP laboratory, professor from Toulouse INP-ENSAT, and President of the Network-Agriville http:// reseau-agriville.com/. Previously, she was an associate professor at the University of Paris VI and a post-graduate in chemistry and Soil Sciences. With a double competence in Biogeochemistry and Sociology, she develops a multi-parameters and multidisciplinary approach within the framework of its research and teaching projects aimed at the ecological transition: rational management of sanitary risks induced by pollutions, urban agriculture, environmental health, changes in agricultural practices, and sustainable urban collective gardens. She was an expert of the National Agency for Food Safety, Environment and Labor (ANSES). She was elected by the National Council for Higher Education and Research (CNESER). She is currently the co-author of about 200 publications and indexed books. Indices $\mathrm{H}=42$ and $\mathrm{iH}=76$.

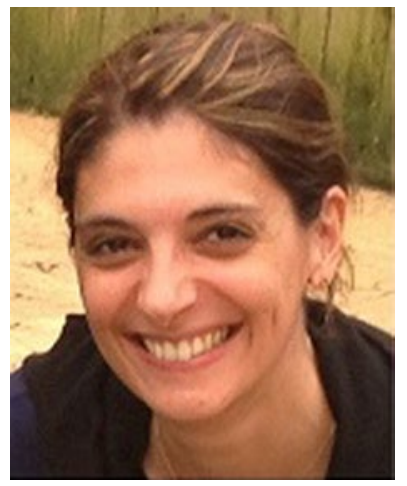

Dr. Aurélie Pelfrêne is a researcher at LGCgE-ISA, Yncréa Lille, France. Over the last 10 years, she dedicated her research to the impact of metallic pollutants on humans. Her work is mainly focused on the following: (i) management of soils affected in varying degrees by human activities and (ii) study of the behavior of pollutants in soils and mechanisms of transfer to human. Her research interest is based on the assessment of human exposure through ingestion and inhalation of soil particles and dust, and consumption of homegrown vegetables cultivated in contaminated soils. Her works take into account the metal bioaccessibility (oral or pulmonary) to promote more proportionate and cost-effective remediation of contaminated land. She is a member of BARGE (Bioaccessibility Research Group of Europe), working to develop harmonized protocols for bioaccessibility testing; member of the editorial board of EGAH journal (Environmental Geochemistry and Environmental Health); and author of around 30 scientific papers in refereed journals.

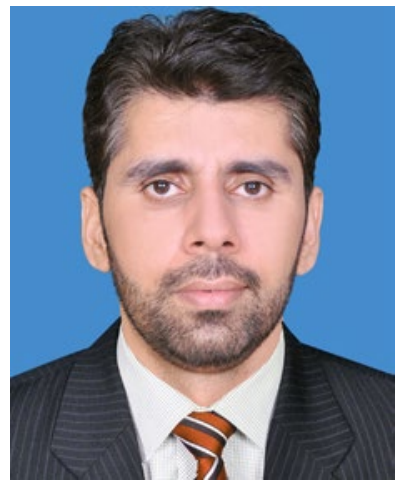

Dr. Muhammad Shahid is currently working as the Associate Professor at the Department of Environmental Sciences, COMSATS University Islamabad, Vehari Campus. His areas of research include drinking water and wastewater analysis and treatment, heavy metal(loid)s biogeochemical behavior in soilplant-human system, remediation of heavy metal(loid)s polluted sites, and plant stress physiology, as well as ecotoxicology and health risk assessment. Till now, he has some 90 research articles, 2 textbooks, and 11 book chapters to his credit. He is a member (PI and Co-PI) of about 17 research projects funded by several national and international funding agencies. 